\title{
Morphological and genetic correlates in the left-right asymmetric scale-eating cichlid fish of Lake Tanganyika
}

\author{
FRANCESCA RAFFINI ${ }^{1,2 \dagger}$, CARMELO FRUCIANO ${ }^{1,3, \dagger}$ and AXEL MEYER MR $^{1,2,4 *}$ \\ ${ }^{1}$ Lehrstuhl für Zoologie und Evolutionsbiologie, Department of Biology, University of Konstanz, \\ Universitätsstrasse 10, 78464 Konstanz, Germany \\ ${ }^{2}$ International Max Planck Research School (IMPRS) for Organismal Biology, University of Konstanz, \\ Konstanz, Germany \\ ${ }^{3}$ School of Earth, Environmental and Biological Sciences, Queensland University of Technology, \\ Brisbane, QLD 4000, Australia \\ ${ }^{4}$ Radcliffe Institute for Advance Study, Harvard University, 9 Garden Street, Cambridge, MA 02138, USA
}

\begin{abstract}
The stable polymorphism in mouth asymmetry in the cichlid fish Perissodus microlepis is a textbook example of adaptive evolution accomplished by functionally relevant morphological changes, ecological specialization and negative frequency-dependent selection. Knowledge about the morphological and developmental basis of this stable polymorphism and the mechanisms driving intraspecific variation in this fish remains largely incomplete. Here, we focus on often-neglected but potentially important aspects of the biology of this fish. In particular, we explore patterns of body shape variation, neutral genome-wide genetic diversity across its geographical distribution, and the presence of asymmetry in eyes centroid size in relationship to mouth bending angle. Geographical space (or a factor associated with geography) has a significant effect on both morphological and genetic diversity, suggesting restricted gene flow across the range of this species. We discuss potential implications of these observed patterns, including the possibility that the genetic basis of asymmetry could vary among locations. A significant association between eye and mouth laterality suggests that the entire head might be involved in the asymmetry. These findings highlight that head asymmetry in P. microlepis is a complex polymorphism involving the interaction of the genetic basis of multiple potentially independent traits and the environment.
\end{abstract}

ADDITIONAL KEYWORDS: biodiversity - cichlid fish - evolution - eye - ddRAD - geometric morphometrics geographical space - interactions - lateralization - negative frequency-dependent selection.

\section{INTRODUCTION}

Adaptive radiations of cichlid fishes in East Africa provide extraordinary model systems for the study of many fundamental questions in evolutionary biology. Cichlids are astonishingly rich in species, adaptations and ecological specializations, many of which evolved repeatedly in each of the three large species flocks of east Africa (reviewed by Meyer, 1993; Kocher, 2004;

*Corresponding author. E-mail: axel.meyer@uni-konstanz.de These authors contributed equally.

*Current address: Institut de biologie de l'Ecole normale supérieure (IBENS), Ecole normale supérieure, CNRS, INSERM, PSL Université Paris, 75005 Paris, France.
Salzburger \& Meyer, 2004; Seehausen, 2006; Salzburger, 2009; Takahashi \& Koblmüller, 2011; Henning \& Meyer, 2014). Cichlids radiations are characterized by the rapid evolution of adaptive feeding modes through morphological changes that permitted ecological specializations (Fryer \& Iles, 1972; Kerschbaumer \& Sturmbauer, 2011; Takahashi \& Koblmüller, 2011). This led to an expansion and successful exploitation of many trophic niches and to effective resource partitioning, facilitating coexistence (reviewed by Sturmbauer, 1998; Gross, Krutzler \& Carlson, 2014).

One of the most notable examples of extreme ecological specialization coupled with functionally relevant morphological adaptation is Perissodus microlepis, a scale-eating cichlid fish endemic to Lake 
Tanganyika (Hori, 1993). Its frequency-balanced polymorphism in the morphology of the mouth, which is not symmetrically placed at the centre of the snout as in most fish but bends asymmetrically either to the left or to the right, is a particularly astonishing adaptation to its feeding behaviour (Hori, 1993). In this scale-eating species, individuals with a right-bending mouth ( $\mathrm{R}$ morph) preferentially feed on scales from the left side of the prey, whereas fish possessing a mouth that bends to the left ( $\mathrm{L}$ morph) mainly attack the prey's right flank. Mouth asymmetry, when attacking the appropriate side, increases the area of contact between the predator's oral cavity and the prey's flank (Nshombo, Yanagisawa \& Nagoshi, 1985; Hori, 1993; Takahashi, Moriwaki \& Hori, 2007; Palmer, 2010; Van Dooren, van Goor \& van Putten, 2010; Lee, Kusche \& Meyer, 2012; Takeuchi, Hori \& Oda, 2012; Takeuchi et al., 2016). This morphological and behavioural laterality contributes to increase hunting success, which is generally very low in scale eaters ( 20\%; Hori, 1987; Takeuchi et al., 2012). The stable presence over time of both $\mathrm{L}$ and $\mathrm{R}$ mouth phenotypes within natural populations is thought to be maintained by negative frequency dependence, through the advantage of the less frequent morph, which better eludes prey's surveillance since victims tend to guard more carefully the side that is more frequently attacked by the more abundant morph (Hori, 1993; Nakajima, Matsuda \& Hori, 2004). Owing to the ecological and evolutionary effects of its lateralized morphology and behaviour, $P$. microlepis became one of the bestknown textbook examples for ecological specialization and balanced polymorphism via negative frequencydependent selection due to prey-predator interactions (Futuyma, 2009).

Recently, however, this famous model has been challenged by several lines of evidence. These include the presence of nearly symmetrical individuals and a likely polygenic nature of mouth asymmetry and, possibly, lateralized behaviour (Hori, 1991; Lee et al., 2010; Palmer, 2010; Stewart \& Albertson, 2010; Van Dooren et al., 2010; Kusche, Lee \& Meyer, 2012; Lee, Heim \& Meyer, 2015; Raffini et al., 2017; Raffini F, Fruciano C, \& Meyer A, unpublished), in contrast to the previously reported bimodal distribution and a simple Mendelian inheritance system that was initially hypothesized and which more easily explained how negative frequency-dependent selection acts on this polymorphism (Hori, 1993; Hori, Ochi \& Kohda, 2007; Stewart \& Albertson, 2010). To accommodate these findings, a more complex picture is emerging, suggesting that the genetic basis of asymmetry also interacts with other processes, potentially including intraspecific competition, physiological trade-offs, as well as random and non-random environmental effects (Palmer, 2010; Stewart \& Albertson, 2010; Takeuchi et al., 2016; Van Dooren et al., 2010; Raffini F, Fruciano C, \& Meyer A, unpublished).

Despite the substantial advances achieved in recent years, our understanding of the morphological and developmental basis of asymmetry and of the mechanisms that determine and drive intraspecific variation in this fish remain largely incomplete. The overall goal of this study is to contribute to a more complete knowledge of this study model, by providing a multi-level analysis of patterns and factors potentially influencing divergence in $P$. microlepis. To this end, we did not only consider variation in mouth asymmetry but also other processes and structures that might contribute to intraspecific polymorphism in this fish, a focus that has been overlooked in previous studies. To date, investigations of $P$. microlepis have focused mainly on mouth polymorphism and its quantitative genetic, environmental and behavioural covariates. This means that potentially important factors, such as restrictions to gene flow across geographical space and variation in other morphological structures, have been largely ignored. For instance, especially for complex phenotypes, restrictions in gene flow can be extremely important because variation in the same trait can be obtained through non-parallel genetic bases (e.g. Borowsky, 2008; Elmer \& Meyer, 2011; Soria-Carrasco et al., 2014; Gross, 2016). Phylogeographical studies in $P$. microlepis conducted so far have been based on only a small number of markers (mitochondrial DNA and microsatellites; Koblmüller et al., 2009; Lee et al., 2010) and, importantly, on a limited portion of this species' range, in the South of Lake Tanganyika.

Likewise, variation in other potentially relevant phenotypic traits has been largely ignored in this species. Detailed and inclusive analyses of variation in morphology can reveal cryptic differences in selection pressures or other underlying processes in natural environments. For example, divergence in external body shape is known to be a key component of intraand interspecific variation and has important fitness consequences (e.g. in fish: Webb, 1978, 1984; Webb \& Weihs, 1986; Pakkasmaa \& Piironen, 2000; Pettersson \& Hedenström, 2000; Boily \& Magnan, 2002; McGuigan et al., 2003; Blake et al., 2005; Fisher \& Hogan, 2007; Langerhans, 2009; Rouleau, Glémet \& Magnan, 2010; Tytell et al., 2010; Franchini et al., 2014; Fruciano et al., 2016a; Senay et al., 2017).

Another trait of potential extreme interest in $P$. microlepis is asymmetry in eye size. In fact, in this fish, the degree of lateralized feeding behaviour has been linked to differences in anatomical size and gene expression between the two hemispheres of several brain regions (Lee et al., 2017). Interestingly, the highest neuroanatomical and transcriptional divergence was 
observed in the tectum opticum, the visual centre of the brain that processes optical information and interacts with motoneurons. More specifically, in this region the hemisphere processing data from the eye that is facing towards the prey during the attack (i.e. the right hemisphere for the left eye and vice versa) was bigger and had different levels of expression for many genes relative to the other hemisphere (Matsumoto \& Hikosaka, 2007; Bianco \& Wilson, 2009; Chen et al., 2009; Gutiérrez-Ibáñez et al., 2011; Ichijo et al., 2017; Lee et al., 2017; Mizumori \& Baker, 2017). It is also known that eyes are an integrated part of the brain; asymmetry in eye use is linked to lateralized behaviour in fish, and preference for a specific eye was shown to be mirrored in an increase of the volume of the corresponding hemisphere in the tectum opticum (Bisazza, Pignatti \& Vallortigara, 1997; Güntürkün, 1997; Bisazza et al., 1998a; Bisazza, Rogers \& Vallortigara, 1998b; Facchin, Bisazza \& Vallortigara, 1999; De Santi et al., 2001; Vallortigara \& Rogers, 2005; Matsui, Takeuchi \& Hori, 2013; Rogers, 1989, 2017). Scale-eating fish most probably use their eyes differentially during lateralized attacks, probably facing prey and coordinating the approach with the eye corresponding to the direction of assault, which might be the preferred one (Takeuchi et al., 2016; Ichijo et al., 2017). Eye function and size are tightly correlated in vertebrates; a bigger eye provides a larger visual field at higher resolution (Easter, Johns \& Baumann, 1977; Hairston, Li \& Easter, 1982; Wilkens \& Strecker, 2003; Werner \& Seifan, 2006; de Busserolles et al., 2013; Champ et al., 2014; Veilleux \& Kirk, 2014). A larger eye on the side towards which the asymmetrical mouth is open probably contributes to improved $P$. microlepis hunting performance, and would thus be favoured by selection. All these lines of evidence suggest that asymmetry in the mouth of $P$. microlepis could be functionally associated with asymmetry in eye size, a correlation that has not been analysed previously in this fish or in other organisms.

Here, we analyse neutral genetic and morphological variation in eye size and body shape in an integrative framework. The aims are to identify genetic and shape variation in geographical space and to put mouth asymmetry in the context of variation of these potentially important morphological traits. In particular, our approach draws power from the analysis of genome-wide single nucleotide polymorphism (SNP) data and advanced morphometric techniques on largely overlapping sets of individuals spanning the distribution range of the species.

\section{MATERIAL AND METHODS}

Two hundred and sixty-eight wild-caught adult $P$. microlepis specimens were collected from five locations in Zambia (April 2010) and three sites in Congo (September 2013; Fig. 1; Supporting Information, Table S1), and preserved in ethanol at $4^{\circ} \mathrm{C}$ (Kusche et al., 2012; Raffini et al., 2017). To avoid

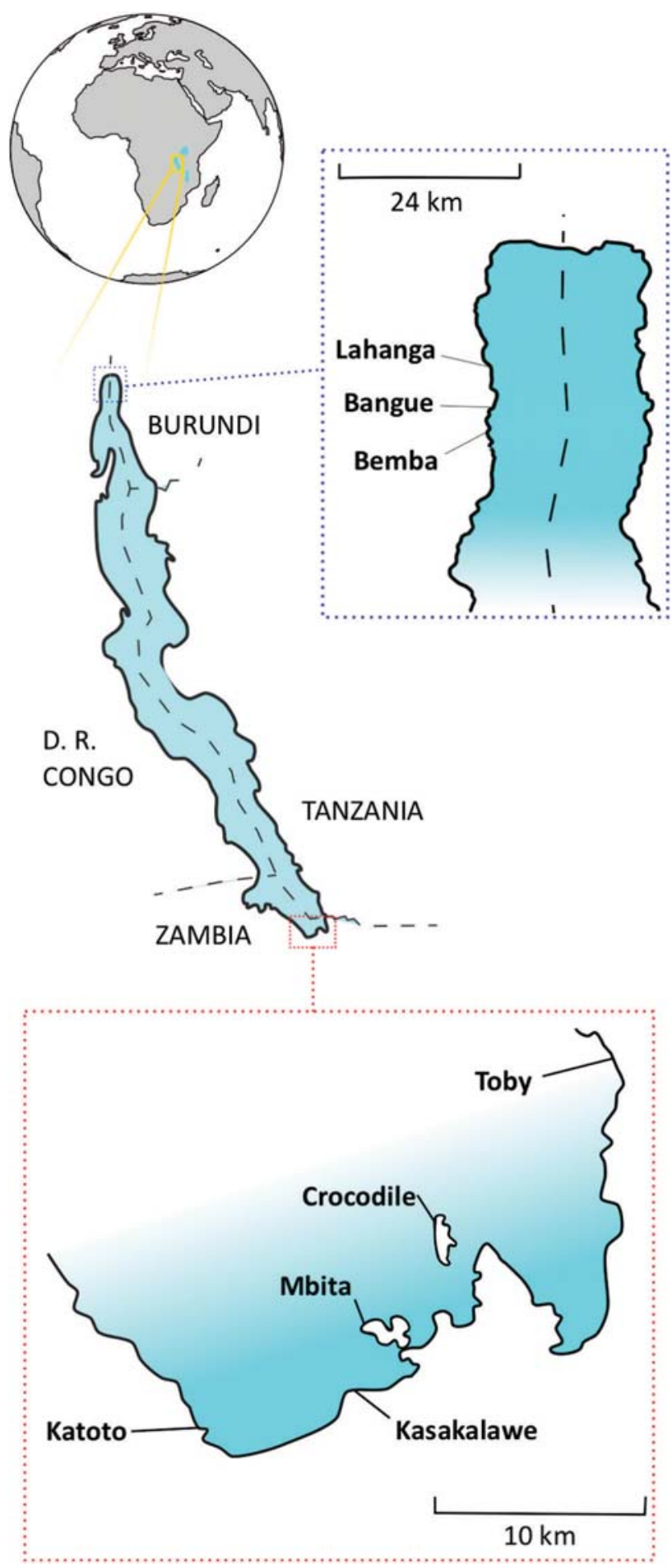

Figure 1. Sampling sites along the northern (Congo) and southern (Zambia) coast of Lake Tanganyika (Africa). 
potential artefacts, 36 fish were excluded from analysis (Supporting Information, Table S1) because pictures were not deemed appropriate to recover morphology (e.g. open mouth).

\section{ACQUISITION OF MORPHOMETRIC DATA AND ANALYSIS OF MEASUREMENT ERROR}

Photographs of the top of the head and both the left and the right side of each specimen were collected with a copy stand and using needles to reduce arching artefacts (Fruciano, Tigano \& Ferrito, 2011b, 2012; Fruciano, 2016). The degree of mouth asymmetry of each individual was retrieved from two previous studies (Raffini et al., 2017; Raffini F, Fruciano C, \& Meyer A, unpublished). Briefly, three landmarks on the most anterior part of the eye sockets and the tip of the snout were digitized as $x, y$ coordinates on the top view pictures using tpsDig v. 2.57 (Rohlf, 2015). These points were used to compute the angle at the left $(\alpha \mathrm{L})$ and right $(\beta R)$ eye. The mouth-bending angle was defined as the difference between these two angles $(\alpha L-\beta R$; in degrees) and used as a measure of asymmetry. Positive values identify those specimens whose mouth bends towards the left, whereas negative values characterize specimens with the mouth opening towards the right (Kusche et al., 2012; Raffini et al., 2017).

To quantify the body shape of our sample of $P$. microlepis, we digitized a set of 33 points, including landmarks, semi-landmarks and 'helper points' (Fig. 2). 'Helper points' are points that are treated as sliding semi-landmarks to aid the alignment of other points, then removed as they do not provide additional information (Zelditch, Swiderski \& Sheets, 2004; Fruciano et al., 2016b). The configurations of

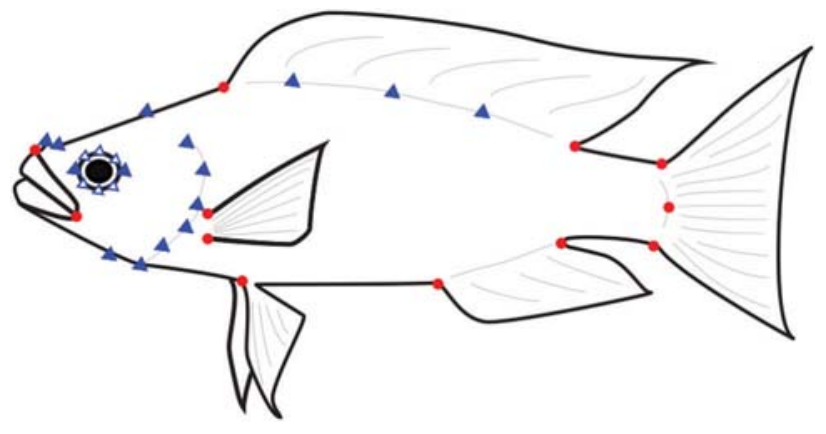

Figure 2. Landmarks (red filled circles), semi-landmarks (blue filled triangles) and helper points (blue open triangles) used to analyse the variation in body shape across Perissodus microlepis populations and asymmetry of the eyes. Here, helper points aid in the alignment of semi-landmarks for the eyes, thus preventing a variation in the digitization of these semi-landmarks relative to the antero-posterior axis of the body from being included in the analysis as a genuine variation in shape. points thus obtained were subjected to a generalized Procrustes analysis with sliding of semi-landmarks (Bookstein, 1997) in tpsRelW 1.54 (Rohlf, 2015).

As substantial non-biological variation can be introduced in geometric morphometric data owing to variation in presentation and digitization (Arnqvist \& Martensson, 1998; Fruciano, 2016), and this might be aggravated in $P$. microlepis by artefactual variation attributable to mouth laterality, we carried out, on a subset of 20 specimens, a preliminary analysis of measurement error (Fruciano, 2016). This allowed us to choose as the experimental design two presentations (pictures) per side and two digitizations per presentation, for a total of eight configurations of points per specimen (two sides $\times$ two presentations $\times$ two digitizations $=$ eight). We also determined that the procedure to remove body arching proposed by Valentin et al. (2008), otherwise useful and successfully used in other studies of fish body shape (Fruciano, Tigano \& Ferrito, 2011a; Fruciano et al., 2012, 2014, 2016a; Franchini et al., 2014; Ingram, 2015), was not appropriate in our case because it was interacting non-linearly with the variation attributable to mouth bending (data not shown). After their alignment with sliding of semi-landmarks, the configurations of points (eight repetitions per specimen) were averaged across repetitions/sides by specimen, thus reducing measurement error (Arnqvist \& Martensson, 1998; Fruciano, 2016). Body centroid size was also computed in tpsRelW for each repetition and averaged by specimen.

To ensure that the experimental design we had chosen was appropriate, we also estimated measurement error on our final dataset of eight configurations of points per specimen. To this end, we performed in MorphoJ (Klingenberg, 2011) a Procrustes ANOVA (Klingenberg \& McIntyre, 1998; Klingenberg, Barluenga \& Meyer, 2002) on the eight repetitions of both sides combined to quantify the relative contribution of variation among individuals, variation between sides of the same individual, and variation attributable to presentation and digitization error. We also performed a Procrustes ANOVA using individual as the only factor, so that we could compute an analogue of the intraclass correlation coefficient (repeatability), as suggested by Fruciano (2016).

To account for allometric variation in shape, we performed a multivariate regression of body shape on body centroid size in MorphoJ and used regression residuals in subsequent analyses.

\section{MORPHOLOGICAL VARIATION IN GEOGRAPHICAL SPACE}

To study body shape variation in geographical space, we used a set of complementary approaches. Using the $R$ package Morpho v. 2.5.1 (Schlager, 2017), we performed 
pairwise permutation tests (10 000 permutations) for the difference in mean shape between sampling sites. Given that we have a nested sampling scheme, we also performed a permutational MANOVA(Anderson, 2001), as implemented in the $\mathrm{R}$ package geomorph (Adams \& Otárola-Castillo, 2013) with a residual randomization procedure for hypothesis testing (Collyer, Sekora \& Adams, 2015), using country as the main factor and location nested within country. As an exploratory tool, we used between-group principal component analysis (PCA; Boulesteix, 2005), as implemented in Morpho (Schlager, 2017). Scatterplots of betweengroup principal component scores are increasingly used in geometric morphometrics (Firmat et al., 2012; Seetah, Cardini \& Miracle, 2012; Fruciano et al., 2014, 2016b, 2017; Schmieder et al., 2015; Franchini et al., 2016) as an alternative to scatterplots of canonical variate scores, because scatterplots of between-group principal component scores do not exaggerate the extent of separation between groups (Mitteroecker \& Bookstein, 2011). Here, as our samples came from distinct countries, Congo and Zambia, we performed between-group PCA using both sampling site and country as groups and we repeated the analysis within countries (Congo or Zambia; Anderson, 2001; Adams \& Otárola-Castillo, 2013; Collyer et al., 2015). In addition to these 'spatially naïve' analyses, we also performed spatially explicit analyses (i.e. statistical analyses that explicitly incorporate spatial information). Spatially explicit approaches are rare in geometric morphometrics (but see Cardini, Jansson \& Elton, 2007; Fruciano et al., 2011a) but have the advantage of describing spatial patterns better and more directly. Here, we use bearing analysis (Falsetti \& Sokal, 1993), as implemented in PASSaGE 2 (Rosenberg \& Anderson, 2011) to test for the presence of a phenotypic cline in geographical space using morphometric data (Fruciano et al., 2011a). Briefly, this analysis tests the correlation between geographical and phenotypic distances using a Mantel test (Mantel, 1967). However, pairwise geographical distances in bearing analysis are weighted relative to an a priori defined direction in geographical space before the Mantel test. A high and significant correlation, then, suggests a cline in geographical space. Here, we tested pairwise distances among individuals for all directions in $5^{\circ}$ increments and using Euclidean distances obtained from the morphometric data.

\section{ANALYSIS OF ASYMMETRY IN EYE SIZE}

To investigate variation in size between the two eyes of each individual, we retrieved the size of each eye of each specimen as the centroid size of the eye's semilandmarks and helper points (Fig. 2). Centroid size was computed for both the right and the left eye of each fish and for each of the four repetitions (two pictures and two digitizations per picture).

An exploratory analysis indicated that the most appropriate index to measure the degree of difference in size between the two eyes is the scaled index FA8 (Palmer, 1994), as suggested by Palmer \& Strobeck (2003). This index was obtained by calculating the logarithm of the ratio between the left and right eye centroid size for each individual, without the use of variance since our focus was at the individual level and not at the population level. The repeatability of FA 8 and centroid size was computed as the intraclass correlation coefficient (Fisher, 1958a). Additionally, we estimated the repeatability of FA8 obtained by averaging repeated measurements (Fleiss \& Shrout, 1977; Arnqvist \& Martensson, 1998). The Shapiro-Wilk normality test (Shapiro \& Wilk, 1965), computed in R, did not show a departure from normality $(P=0.208)$. The relationship between FA8 and the mouth bending angle was assessed using the Pearson correlation coefficient and tested by performing multiple linear regression in $\mathrm{R}$. In particular, our linear model had FA8 as the dependent variable and mouth bending angle, body centroid size (as proxy for fish age, another factor that could contribute to asymmetry; Raffini F, Fruciano C, \& Meyer A, unpublished) and their interaction as predictors. The interaction was visualized by plotting the effect of one predictor variable on the coefficients of the other using the $R$ package interplot (Solt \& Hu, 2015).

\section{GENETIC DIFFERENTIATION}

A genome-wide array of SNPs developed in a previous study (Raffini et al., 2017) was used to explore geographical genetic variation. In contrast to our former study, we analysed the three sampling locations in the northern part of Lake Tanganyika (Democratic Republic of Congo) as distinct sampling sites, notwithstanding their small sample size. Fortyfour individuals (Supporting Information, Table S1) were individually sequenced using the doubledigested restriction-associated DNA tags (ddRAD) sequencing approach (Miller et al., 2007; Baird et al., 2008; Peterson et al., 2012), obtaining 94717 SNPs after removal of loci significantly deviating from the Hardy-Weinberg equilibrium and of the locus containing the SNP 56537-113 that we previously identified as differentiated between the left and right morph (molecular and bioinformatics pipelines described by Raffini et al., 2017). The removal of these loci allowed our patterns to be dominated by neutral genetic variation. 
The Stacks v. 1.35 populations module (Catchen et al., 2013) was used to analyse genetic differentiation between locations. The minimum percentage of individuals in a population required to process a locus for that population (-r) was set at 0.4 , together with five individual minimum stack depth required for individuals at a locus $(-\mathrm{m})$. Pairwise $F_{\mathrm{ST}}$ (Weir \& Cockerham, 1984; Nielsen \& Beaumont, 2009) and corresponding $P$-values according to the Fisher's exact test (Fisher, 1958b) were computed for each locus. These $P$-values were corrected for multiple tests in SGOF+ v. 3.8 (Carvajal-Rodriguez \& de UñaAlvarez, 2011) using the Benjamini \& Hochberg (1995) correction method. The genome-wide bootstrapped $F_{\text {ST }}$ (Wright, 1949; Weir \& Cockerham, 1984) for each pairwise comparison was computed using 1000 bootstrap samples with the R library StAMPP (Pembleton, Cogan \& Forster, 2013). ARLEQUIN v. 3.5 (Excoffier \& Lischer, 2010) was used to perform hierarchical analyses of molecular variance (AMOVA, 10000 permutations; Excoffier, Smouse \& Quattro, 1992) with locations nested in country. Accordingly, genetic variation is partitioned into four components: between countries; among locations within country; among individuals within locations; and within individuals. For this analysis, three random subsets of $10000 \mathrm{SNPs}$ were generated through the procedure reported in the Stacks documentation.

The correlation between individual genetic (Prevosti distance calcolated in $\mathrm{R}$ v. 3.3.3 using the package poppr v. 2.2.1; Prevosti, Ocaña \& Alonso, 1975; Kamvar, Tabima \& Grünwald, 2014; R Core Team, 2016) and spatial (coastal distances in kilometres) distances was tested by performing a Mantel test ( $\mathrm{R}$ package vegan v. 2.4-1; Oksanen et al., 2016) using 999 permutations and the Spearman correlation. Maximum likelihood estimation of individual ancestries was run in Admixture v. 1.23 (Alexander, Novembre \& Lange, 2009). This analysis was performed for $K$ (number of clusters) ranging from one to ten and implementing the cross-validation (CV) procedure to identify the most likely subdivision in clusters. The outputs of these tests were plotted using R. A PCA was computed using the R library adegenet v. 1.4-2 (Jombart \& Ahmed, 2011). As a further tool to visualize the genetic relationship between the geographical sites, we computed a neighbor-joining (NJ) tree (Saitou \& Nei, 1987) based on the Prevosti distance using the R library ape (Paradis, Claude \& Strimmer, 2004). The same matrix of distances was used to perform a bearing analysis. Demographic parameters, such as the number of segregating sites and the neutrality indices Tajima's $D, \mathrm{Fu}$ and Li's $F$ and Fu and Li's $D$ (Tajima, 1989; Fu \& Li, 1993), were computed both individually for each population and pooling individuals by country (Congo or Zambia) using the $\mathrm{R}$ package PopGenome
(Pfeifer et al., 2014). The populations Bemba and Bangue were excluded from neutrality tests due to their small sample sizes.

\section{COMBINED ANALYSIS OF GENETIC AND MORPHOMETRIC DATA}

For the fish with both genetic and morphometric data $(N=44$; Supporting Information, Table S1), we computed the correlation between Euclidean distances of the morphometric dataset and Prevosti distances of the genetic dataset. We then tested this correlation with a Mantel test. Furthermore, we tested for the correlation of genetic and morphometric distances while controlling for geographical linear distances using a partial Mantel test (Smouse, Long \& Sokal, 1986). As Mantel and partial Mantel tests have encountered much criticism (e.g. Legendre \& Fortin, 2010; Guillot \& Rousset, 2013), we used a complementary and conceptually similar approach to ensure the robustness of our results. Here, we performed a principal coordinate analysis on the matrix of Prevosti distances, retaining the first 27 axes (i.e. all the dimensions accounting for $\geq 1 \%$ of variance). Then we fitted two separate linear models using as a predictor the matrix of latitude and longitude coordinates and as response the shape data and the principal coordinates of the genetic data, respectively. We then used a two-block partial least squares analysis (Rohlf \& Corti, 2000), as implemented in geomorph, to assess and test for the association of the two sets of residuals (shape and genetic) obtained from the linear models.

\section{RESULTS}

The Procrustes ANOVA we performed to quantify measurement error and variation between sides revealed a substantial and significant proportion of variation attributable to side and presentation (picture), with $\sim 10 \%$ of variance explained by each of the terms side, individual $\times$ side and presentation (Supporting Information, Table S2). Repeatability across the eight configurations per individual (two sides $\times$ two pictures $\times$ two digitizations) was moderate (0.75). Overall, these results on the full dataset reinforce our choice, based on a preliminary analysis, of taking repeated measurements and averaging them as a sensible method to reduce measurement error.

\section{VARIATION IN GEOGRAPHICAL SPACE}

Performing exploratory between-group PCA of morphological differentiation using all sampling sites with country as a group reveals a very high degree 
of overlap among sampling sites (Fig. 3A), but some level of separation of specimens from Zambia and specimens from Congo (Fig. 3B). This pattern becomes clearer when performing a between-group PCA using country as a group, with scores along the first between-group principal component showing distinct (but overlapping) distributions for Zambia and Congo (Fig. 3B, C). The direction of variation between country means shows that, after controlling for allometry, $P$. microlepis from Congo are slightly more elongated compared with fish from Zambia (Fig. 3D). Performing a between-group PCA within countries reveals a good separation only between Congo sampling sites (Fig. 3E, F). The bimodal distribution of the scores on the country between-group PCA for the Congolese samples (Fig. 3C) is probably attributable to the good separation of the Congolese sampling sites from each other (Fig. 3E) and the fact that the two betweengroup principal component axes computed for Congo samples only (Fig. 3E) are relatively similar (i.e. account for similar shape change; data not shown) to the between-group principal component axis obtained using country as a group.

Tests of difference in mean shape between sampling sites (Table 1) reveal overall significant differences among sampling sites, with non-significant differences restricted to sites with small sample sizes, where the absence of a significant difference in means can be attributed to lack of statistical power. Significant differences in mean shape between countries $(P<0.0001)$ mirror the exploratory results obtained with between-group PCA. The permutational MANOVA with residual randomization procedure with location as a nested factor within country confirms that, although there are significant differences between countries and between sampling sites within countries, most of the variation among individuals is not accounted for by these two terms, with the residuals explaining $\sim 84.5 \%$ of total variance [country: mean squares $(\mathrm{MS})=0.0129, F_{1,266}=15.400$, $P=0.001$; location nested in country: MS $=0.0045$, $F_{6,266}=5.352, P=0.001$; residuals: d.f. $=259,266$, $\mathrm{MS}=0.0008]$. Bearing analysis failed to detect a clear cline in geographical space (Supporting Information, Fig. S1A). In fact, except for a small range of directions $\left(15-25^{\circ}\right)$ where correlation is even lower, for all the other angles tested the correlation was significant but always low and with a restricted range of values (0.16-0.19). This suggests that there is a relationship between geographical and morphological distances, but not along a precise cline.

The analyses of genome-wide differentiation between sampling sites were all highly significant (Table 2). The $F_{\mathrm{ST}}$ values increased with growing coastal distance, except that the Congo locations show lower differentiation from Mbita than the other Zambian populations. This overall trend was in agreement with the results of the Mantel test, exhibiting a significant correlation between genetic and spatial distances (Mantel's $r=0.625 ; P=0.001$ ).

The AMOVA analyses indicated that differentiation between countries and locations is significant and accounts for 30 and $5 \%$ of genetic variation respectively; 48 and $17 \%$ of genetic variance is explained by the between- and within-individual component, respectively (Table 3). Principal component analysis and NJ tree (Supporting Information, Figs S2, S3) were concordant in suggesting that most of the genetic variation is found between Congo and Zambia, followed by the four Zambian populations, with a considerable overlap between Kasakalawe and Mbita. This was confirmed by the estimation of individual ancestries (Fig. 4), which identified two clusters of individuals corresponding to Congo and Zambia, and three (best supported by the CV procedure; Supporting Information, Fig. S4) or four clusters corresponding to the four Zambia populations, with weak distinction between Kasakalawe and Mbita. The three populations in Congo were not genetically differentiated in any analysis. Negative values of the neutrality tests suggested that Congo and Zambia (population pooled by country) had an excess of rare alleles associated with recent population expansion or the occurrence of positive selection (Supporting Information, Table S3). At the individual population level, positive neutrality statistics in Lahanga, Katoto and Toby might indicate potential population bottleneck or balancing selection events. Bearing analysis on Prevosti distances revealed a pattern qualitatively similar to the one shown by morphometric distances, with most directions having very similar and significant levels of correlation between genetic distances and geographical distances (Supporting Information, Fig. S1B). The main difference between the results of the bearing analysis based on morphometric and genetic data is that genetic data show higher correlations (0.59-0.65).

\section{COMBINED ANALYSIS OF GENETIC AND MORPHOMETRIC DATA}

Individuals having both genetic and morphometric data were tested for correlations between morphometric and genetic distances, which were low but significant (Mantel test, $r=0.17, P=0.003$ ). However, when controlling for geographical distances using a partial Mantel test, the correlation was nullified and not significant $(r=-0.01, P=0.56)$. Our complementary analysis based on a PCA of genetic distances, linear models accounting for geographical location and partial least squares analysis to test for association of the residuals mirrored our results based on the partial Mantel test. Indeed, the correlation 

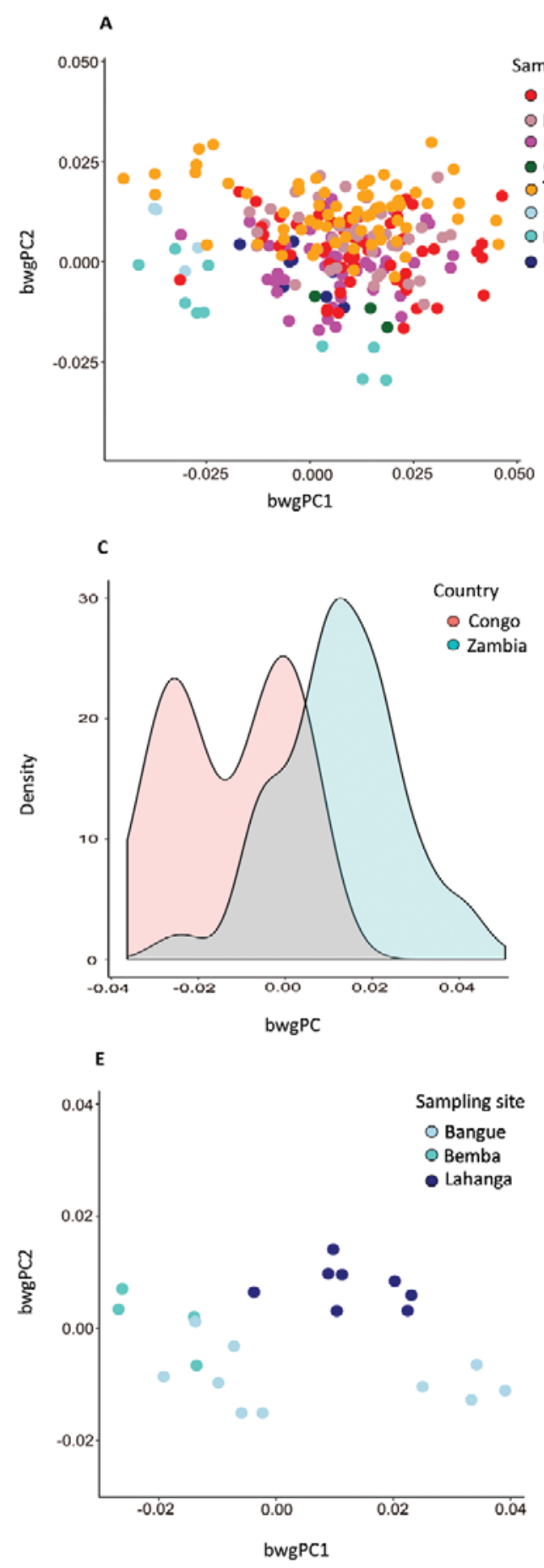

B

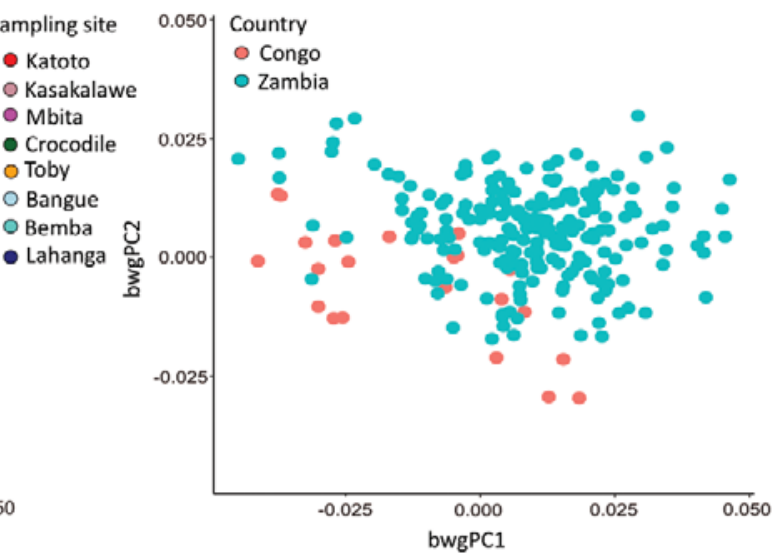

D
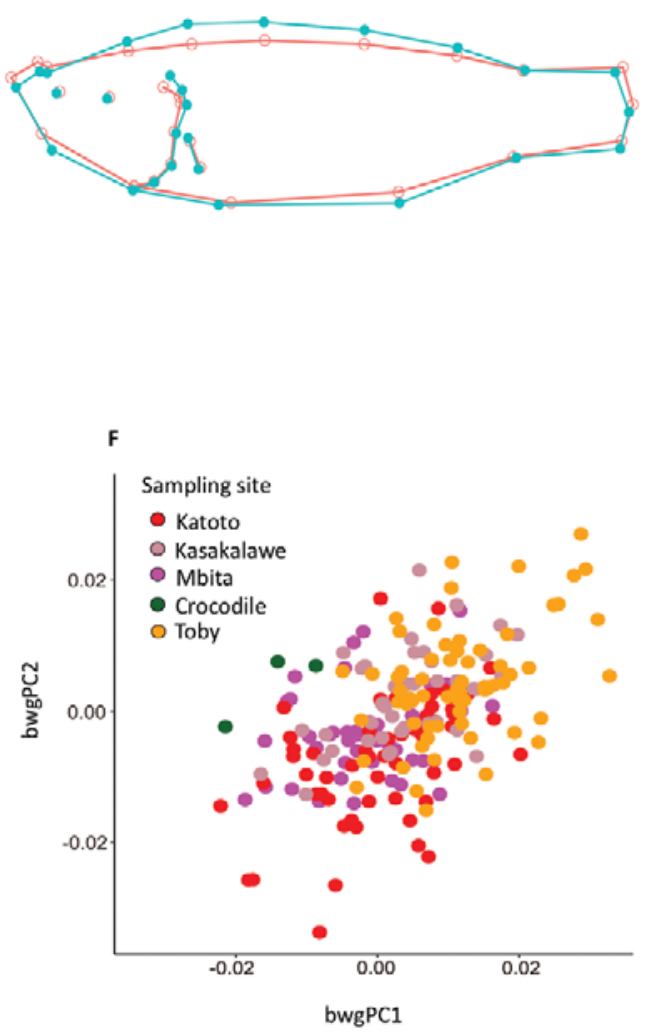

Figure 3. Morphological variation in the geographical space. A, B, plot of the scores along the first two between-group principal components (sampling site used as group), with colour-coding for sampling sites (A) or countries (B). These two axes cumulatively account for $58.54 \%$ of variance among individuals. C, density plot of the scores along the between-group principal component using country as the group (this component accounts for $35.29 \%$ of the variance among individuals). D, variation in body shape between the two countries (difference in mean shape, exaggerated twofold). E, F, plot of the scores along the first two between-group principal components (sampling sites used as group), analysing each country separately: Congo (E; accounting for 38.67 and $8.85 \%$ of variance) and Zambia (F; accounting for 18.67 and $5.05 \%$ of variance). Abbreviation: bwgPC, between-group principal component. 
Table 1. Morphological differentiation between Perissodus microlepis sampling sites

\begin{tabular}{lrrrrrrrr}
\hline Distance, $P$-value & \multicolumn{1}{c}{ Bemba } & Bangue & Lahanga & Katoto & Kasakalawe & Mbita & Crocodile & Toby \\
\hline Bemba & \multicolumn{1}{c}{} & 0.2947 & 0.0335 & 0.0453 & 0.0443 & 0.0420 & 0.0486 & 0.0408 \\
Bangue & $\mathbf{0 . 0 2 2 4}$ & - & 0.0176 & 0.0312 & 0.0318 & 0.0258 & 0.0267 & 0.0333 \\
Lahanga & $\mathbf{0 . 0 1 0 0}$ & 0.1360 & - & 0.0189 & 0.1920 & 0.0141 & 0.0335 & 0.0186 \\
Katoto & $<\mathbf{0 . 0 0 0 1}$ & $<\mathbf{0 . 0 0 0 1}$ & $\mathbf{0 . 0 2 1 2}$ & - & 0.0190 & 0.0091 & 0.0190 & 0.0165 \\
Kasakalawe & $<\mathbf{0 . 0 0 0 1}$ & $\mathbf{< . 0 0 0 1}$ & $\mathbf{0 . 0 2 2 7}$ & $\mathbf{0 . 0 1 1 1}$ & - & 0.0115 & 0.0196 & 0.0115 \\
Mbita & $\mathbf{0 . 0 0 0 1}$ & $\mathbf{0 . 0 0 0 2}$ & 0.1357 & $\mathbf{0 . 0 3 5 7}$ & $\mathbf{0 . 0 1 2 1}$ & - & 0.0164 & 0.0159 \\
Crocodile & $\mathbf{0 . 0 0 2 4}$ & 0.0812 & 0.3121 & 0.2360 & 0.2155 & $\mathbf{0 . 4 0 3 5}$ & - & 0.0265 \\
Toby & $\mathbf{0 . 0 0 0 2}$ & $<\mathbf{0 . 0 0 0 1}$ & $\mathbf{0 . 0 2 2 3}$ & $<\mathbf{0 . 0 0 0 1}$ & $\mathbf{0 . 0 0 5 0}$ & $<\mathbf{0 . 0 0 0 1}$ & $\mathbf{0 . 0 4 6 8}$ & - \\
\hline
\end{tabular}

Procrustes distances and associated $P$-values are reported in the upper and lower triangle, respectively. Statistically significant $(P<0.05)$ comparisons are highlighted in boldface.

Table 2. Genetic differentiation between Perissodus microlepis sampling sites

\begin{tabular}{llllllll}
\hline $\begin{array}{l}F_{\text {ST }}, \\
\text { Number of } \\
\text { loci }\end{array}$ & Bemba & Bangue & Lahanga & Katoto & Kasakalawe & Mbita & Toby \\
\hline Bemba & - & 0.0242 & 0.0267 & 0.5297 & 0.5387 & 0.4999 & 0.6033 \\
Bangue & 0 & - & 0.0227 & 0.5501 & 0.5548 & 0.5253 & 0.6153 \\
Lahanga & 0 & 0 & - & 0.5476 & 0.5573 & 0.5202 & 0.6116 \\
Katoto & 7948 & 5801 & 8630 & - & 0.1177 & 0.1041 & 0.2252 \\
Kasakalawe & 4333 & 4736 & 6762 & 528 & - & 0.0316 & 0.1589 \\
Mbita & 6505 & 5503 & 8022 & 921 & 2 & - & 0.1391 \\
Toby & 8511 & 6161 & 9000 & 1301 & 766 & 1301 & - \\
\hline
\end{tabular}

Pairwise $F_{\mathrm{ST}}$ are reported in the upper triangle; all the comparisons were statistically highly significant $(P<0.01)$. The lower triangle indicates the number of loci significantly differentiated between locations after the correction for multiple tests.

between the singular scores (partial least squares scores) of the genetic and morphometric blocks was low and not significant $(r=0.38, P=0.39$ ). These results together suggest that, although both genetic and morphometric data show significant and 'diffused' variation in geographical space (i.e. variation that does not follow a precise cline) and although genetic and morphometric variation are correlated, these patterns are attributable to geographical distances.

\section{VARIATION IN EYE ASYMMETRY}

Next, we analysed the relationship between eye size and mouth asymmetry. The repeatability of the centroid size measurement was 0.94 and 0.92 for the left and right eye, respectively, and it was 0.54 for FA8. Therefore, we used the mean of repeated centroid size measurements to compute FA8, which improved the repeatability of this index to 0.82 . Asymmetry in the eye size was significantly associated with mouth laterality (Fig. 5A; Pearson's product-moment correlation: $r=0.22, t=3.596$, d.f. $=264, P=0.0004$; linear regression: $R^{2}=0.047, F_{1,264}=12.93, P=0.0004$ ). The difference in size between the two eyes increased with growing mouth bending angle, and the direction of asymmetry in the eye mirrored the one in the mouth; that is, individuals with a mouth bending towards the right (negative mouth angle values) showed a bigger right eye (negative FA8 values), and vice versa. Body size had a significant effect on eye asymmetry and on the coefficients of mouth bending angle in the interaction term (Table 4; Fig. 5B, C).

\section{DISCUSSION}

Perissodus microlepis is famously known for its intraspecific polymorphism in mouth shape, which is thought to represent an adaptation to its specialized feeding mode (Hori, 1993). Nonetheless, patterns of external morphological variation and neutral genomic diversity in this cichlid fish remain largely unstudied, although they could contribute to a more comprehensive understanding of this striking study system. We combined genomic and geometric morphometric approaches to explore body shape variation and genetic neutral diversity in geographical space. Additionally, we investigated the presence of divergence in eye size and its association with mouth asymmetry. Our results suggest that body morphology 
Table 3. Genetic variation among and within countries, locations and individuals

\begin{tabular}{lllll}
\hline \multirow{2}{*}{ Source of variation } & & Dataset & & \\
\cline { 3 - 4 } & & Random subset 1 & Random subset 2 & Random subset 3 \\
\hline Between countries & Sum of squares & 42972.288 & 42403.042 & 43011.006 \\
& Variance components & 1273.667 & 1251.681 & 1272.800 \\
& Percentage of variation & 30.473 & 29.913 & 30.222 \\
Among locations within country & Sum of squares & 36519.379 & 36814.466 & 36815.493 \\
& Variance components & 203.780 & 203.440 & 202.688 \\
Among individuals within locations & Percentage of variation & 4.875 & 4.862 & 4.813 \\
& Sum of squares & 174231.129 & 176575.083 & 176936.989 \\
& Variance components & 2006.759 & 2042.968 & 2046.148 \\
Within individuals & Percentage of variation & 48.013 & 48.823 & 48.586 \\
& Sum of squares & 30599 & 30200 & 30350.500 \\
Total & Variance components & 695.432 & 686.364 & 689.784 \\
& Percentage of variation & 16.639 & 16.403 & 16.379 \\
& Sum of squares & 284321.795 & 285992.591 & 287113.989 \\
& Variance components & 4179.637 & 4184.452 & 4211.420 \\
\hline
\end{tabular}

Hierarchical analyses of molecular variance (AMOVA). All the tests were statistically highly significant $(P<0.01)$.

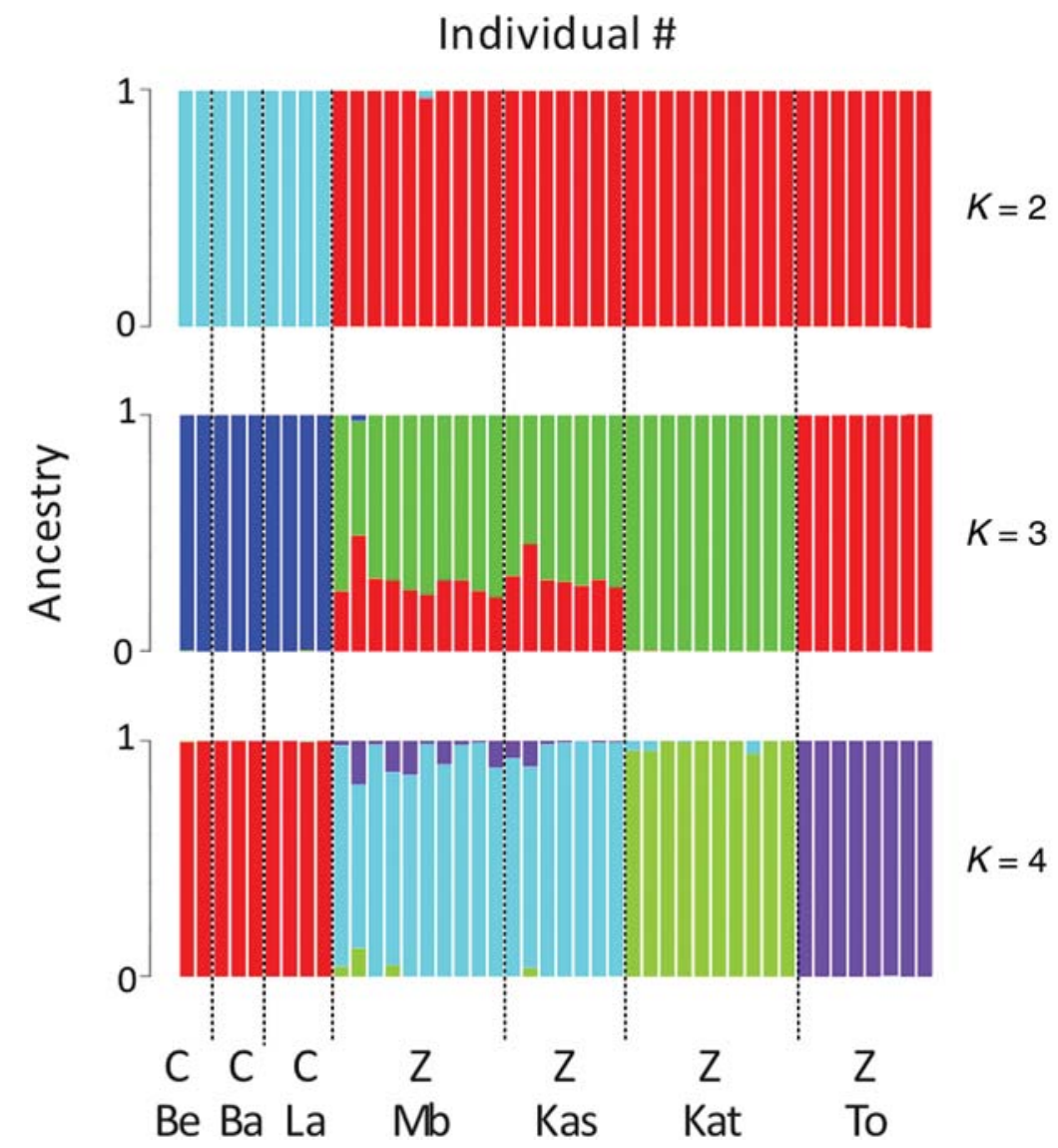

Figure 4. Genetic relationship between geographical sites: Admixture barplots for the genetic dataset using values of $K$ from two (upper plot) to four (lower plot). Each vertical line represents an individual, and the colours within each line correspond to the inferred proportion of ancestry. Populations are separated by black dotted vertical lines. Abbreviations: Ba, Bangue; Be, Bemba; C, Congo; La, Lahanga; Kas, Kasakalawe; Kat, Katoto; Mb, Mbita; To, Toby; Z, Zambia. 

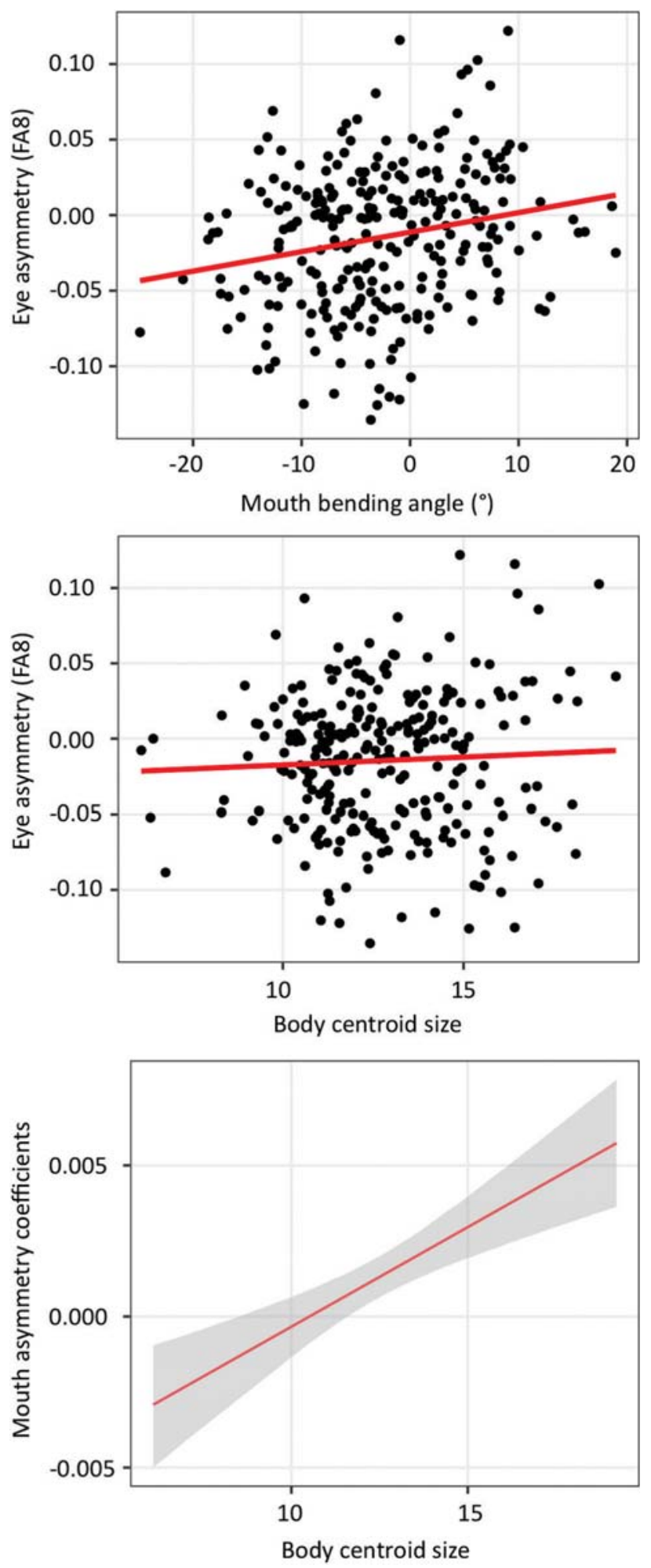

Figure 5. The relationship between eye asymmetry, mouth asymmetry and body centroid size. A, B, plot of the association between asymmetry in eye size (FA8 index) and degree of mouth bending angle (A) or body centroid size (B). $\mathrm{C}$, interaction between body size and mouth bending angle: and neutral genetic variation are explained by geography (or a factor associated with geography), and that the mouth bending angle is correlated with the amount and direction of asymmetry in eye size. These findings add to the growing evidence that multiple factors and structures underlie intraspecific polymorphism in P. microlepis.

\section{GEOGRAPHY UNDERLIES BODY MORPHOLOGICAL AND GENOME-WIDE VARIATION}

Geography was a major predictor of genetic and morphological variation between sampling sites in P. microlepis, although a precise cline was not detected. As expected, the two countries Congo and Zambia, which represent the northern and southern end of the Lake Tanganyika, respectively, and are separated by $\sim 660$ $\mathrm{km}$, account for most of the variation. This geographical effect could be linked to multi-directional patterns of isolation-by-distance, as seen at a much smaller spatial scale along Zambian rocky shorelines using mitochondrial DNA (sampling localities separated by a few dozen kilometres; Koblmüller et al., 2009). It could also reflect changes in the network dynamics of populations, for example due to fluctuations in the lake level originating and reshuffling barriers to gene flow. Intermittent connectivity, oscillations in population size and colonization events are known to affect diversity distribution (examples in Lake Tanganyika cichlids: Koblmüller et al., 2011; Nevado et al., 2013; Sefc et al., 2017). Our genetic data showed signatures of population expansion in Congo and Zambia (locations pooled by country), whereas it revealed bottlenecks in three local populations (Lahanga, Katoto and Toby). This partial discrepancy between large and small spatial scale could emerge from reduced sample sizes of non-pooled populations or might reflect differences in microevolutionary histories (e.g. between eastern and western Zambia populations; Koblmüller et al., 2009). Larger sample sizes and estimates of mutation rates might allow discrimination between these two scenarios and provide divergence time estimates to be compared with geological events in the area (e.g. fluctuations in the lake's level; see, for example, Sefc et al., 2017).

Another factor potentially affecting geographical diversity is the presence of spatial variation in ecological cues (e.g. environmental abiotic and biotic factors) and/or selective regimes, as repeatedly shown in the Tanganyikan cichlid fish radiations (e.g. Clabaut et al., 2007; Day, Cotton \& Barraclough, 2008;

interplot showing how a change in body size (as a proxy for fish age) affects the coefficient of mouth asymmetry in the model. Shaded area represents the $96 \%$ confidence interval. 
Muschick, Indermaur \& Salzburger, 2012; Janzen et al., 2017). These between-species comparative studies revealed that environmental and ecological differences play a key role in generating morphological diversity and barriers to gene flow potentially attributable to divergent selection, and it might be also the case for $P$. microlepis within-species populations. Northern and southern lake shores present different abiotic features, such as water depth or type of bottom (steeper, deeper and considerably more sandy in Congo; Coenen, Hanek \& Kotilainen, 1993; International Lake Environment Commitee, 1999-2017). In line with this habitat variation, we found that fish from Congo are on average more streamlined compared with fish from Zambia, similar to the more elongated bodies observed in cichlids inhabiting deeper waters (Clabaut et al., 2007). Additionally, the scale-hunting technique of this scale eater includes quick body flexions and aggressive mimicry (hiding itself between schools of prey or other fish thanks to its close resemblance to these species in overall body shape and colour; Supporting Information, Fig. S5; Hori \& Watanabe, 2000; Koblmüller et al., 2007, 2009; Takeuchi et al., 2012). The morphological variation in the body could be influenced by local community structure and mirror the natural phenotypic diversity of prey across Lake Tanganyika. The slender body presented by $P$. microlepis in northern Congo might be beneficial for improving swimming ability (as shown in other fishes; e.g. Webb, 1978, 1982, 1984; Webb, Kostecki \& Stevens, 1984; Webb \& Weihs, 1986; Blake et al., 2005; Langerhans, 2009; Rouleau et al., 2010; Senay et al., 2017) and removing scales from prey, which might naturally include faster swimmers or more limnetic species. Alternatively, the northern schooling fishes could be more arrow shaped than the Zambian populations and, consequently, $P$. microlepis evolved a more streamlined body for better camouflage. Differences between fish populations related to aggressive mimicry have been shown for colour polymorphism (e.g. in fish: Munday, Eyre \& Jones, 2003; Maan \& Sefc, 2013) but, to our knowledge, they have not yet been described for body morphological variation. In $P$. microlepis, mimicry and predator-prey associations have been proposed to underlie anal fin colour polymorphism (Hori \&
Watanabe, 2000) and to generate a barrier to gene flow in the Mbete Bay (Zambia; Koblmüller et al., 2009), and these mechanisms might also be involved at a larger morphological, genomic and spatial scale in body shape and neutral genome-wide divergence across Lake Tanganyika, possibly as by-product of adaptation to local environments, including ecological interactions. However, our results show that phenotypic variation in geographical space is largely explained by geographical distances; thus, we cannot distinguish between neutral and adaptive processes (Shafer \& Wolf, 2013).

A more nuanced investigation including populations sampled between Congo and Zambia, information about local community structure and deeper demographic analyses might help to clarify the relative contribution of biological and abiotic cues, natural selection and neutral processes in shaping intraspecific polymorphism in P. microlepis. In this fish, geography does not seem to influence asymmetry in the mouth, at least within Zambia (Kusche et al., 2012; Lee et al., 2010); however, a more detailed and spatially explicit framework could reveal unforeseen patterns and relationships.

\section{ASYMMETRY IN THE VISUAL SYSTEM IS LINKED TO MOUTH POLYMORPHISM}

Asymmetry in neuronal circuits in sensory and/or motor systems (tectum opticum, habenula and M-cells) has recently been linked to lateralized behaviour or mouth asymmetry of $P$. microlepis (Takeuchi et al., 2012, 2016; Ichijo et al., 2017; Lee et al., 2017; Takeuchi \& Oda, 2017). Here, we showed that the eyes, an integrated part of the brain, are asymmetrical in size, and this polymorphism is associated with the asymmetry in the mouth. In the light of the significant relationship between transcriptional and neuroanatomical asymmetry in the tectum opticum and lateralized attacking predilection (Lee et al., 2017), and between eye preference and the volume of the corresponding tectum opticum's hemisphere shown in other organisms (Rogers, 1989, 2017; Bisazza et al., 1997, 1998a, 1998b; Güntürkün, 1997; Facchin et al., 1999; De Santi et al., 2001; Vallortigara \& Rogers, 2005; Matsui et al., 2013), eye asymmetry in $P$. microlepis could be correlated with both mouth

Table 4. The relationship between eye asymmetry, mouth bending angle and body centroid size as modelled in a general linear regression model

\begin{tabular}{|c|c|c|c|c|c|}
\hline Explanatory variable & d.f. num, den & Estimate & $\mathrm{SE}$ & $t$ & $P$-value \\
\hline Mouth angle & 1,262 & -0.0069 & 0.0019 & -3.602 & 0.0004 \\
\hline Body size & 1,262 & 0.0025 & 0.0013 & 2.010 & 0.0454 \\
\hline Mouth angle:body size & 1,262 & 0.0066 & 0.0001 & 4.339 & $2.05 e^{-05}$ \\
\hline
\end{tabular}

Abbreviations: den, denominator; d.f., degree of freedoms; num, numerator. Statistically significant $(P<0.05)$ results are highlighted in boldface. 
asymmetry (as shown in the present study) and lateralized behaviour. The polymorphism in the eyes might be adaptive, because improved vision (bigger eye) and visual processing (larger tectum opticum) on the side at which scale eaters approach prey is likely to be beneficial for hunting success.

We observed a significant association between body size (a proxy for age; Raffini F, Fruciano C, \& Meyer A, unpublished) and asymmetry in both the eyes and the mouth, and a significant interaction between body size and mouth asymmetry; the positive relationship between eye asymmetry and mouth asymmetry becomes stronger in larger fish. Direct and indirect evidence indicates that the amount of mouth asymmetry is influenced by feeding experience (Stewart \& Albertson, 2010; Van Dooren et al., 2010; Kusche et al., 2012; Lee et al., 2015; Takeuchi et al., 2016; Raffini F, Fruciano C, \& Meyer A, unpublished) and that lateralized behaviour is established during development through practice; fish initially attack prey on both flanks and learn on which side they are more efficient in removing scales, depending on their asymmetrical mouth and lateralized kinetics (Takeuchi et al., 2016; Takeuchi \& Oda, 2017). Our findings might also suggest that other morphological structures, such as the eyes, contribute to this dynamic, since asymmetry of the eyes size mirrored that of the mouth and, possibly, behaviour laterality. Vision could be adjusted plastically during growth to match asymmetry in the mouth and thus improve hunting success, or a larger eye on the side towards which the mouth opens might increase the amount of fruitful attempts during correctly directed lateralized attacks, leading to a more asymmetrical mouth due to the plastic effects of the higher number of ingested scales (through the mechanism described by Raffini F, Fruciano C, \& Meyer A, unpublished). Owing to the presence of left-right differences in eyes size, the two tectum opticum hemispheres most probably receive and/or process asymmetrical visual information that is then output to downstream cerebral structures. This asymmetrical flow might possibly contribute to the establishment of lateralized neuronal circuits, for example in the habenula or hindbrain (M-cells), which are known to be involved in motor responses to visual stimuli and have been proposed to play a key role in P. microlepis asymmetry (Takeuchi et al., 2016; Ichijo et al., 2017; Lee et al., 2017; Takeuchi \& Oda, 2017).

Taken together, these findings on eyes provide the first indication of lateralization in eye size (and, indirectly, eye function) related to asymmetry in the mouth and, possibly, in the brain and behaviour; an association that has been overlooked in this and other organisms. We advocate future studies to explore this multi-level interrelationship further, particularly its genetic or non-genetic basis (at present relatively clear only for mouth asymmetry) and its relative role and timing in the developmental and evolutionary establishment and maintenance of laterality in this cichlid fish.

\section{CONCLUSION}

In summary, in this study on $P$. microlepis we have focused on a suite of traits and features largely overshadowed by the striking mouth polymorphism of this species. In particular, we document a reduction in gene flow across Lake Tanganyika, which opens the possibility that the genetic basis of mouth asymmetry could vary among locations. Perhaps most importantly, we show that functionally relevant traits (body shape) vary over large-scale geographical distances and that there is an association between eye and mouth asymmetry, thus suggesting the possibility that variation in these traits interacts with the genetic basis of mouth asymmetry and the environment to produce (and, possibly, to maintain over time) the striking variation in mouth asymmetry of $P$. microlepis.

\section{ACKNOWLEDGEMENTS}

We thank Henrik Kusche and Gabriele Legant for help in collecting fishes in 2010, and Stephan Koblmüller and Christian Sturmbauer in 2013. We are grateful to Niclas Kolm and Ralf Schneider for useful suggestions about eye asymmetry. We thank two anonymous reviewers for their helpful comments. F.R. is supported by the International Max Planck Research School (IMPRS). C.F. was partially funded by a Marie Curie IEF Fellowship (Grant Agreement 327875 PlasticitySpeciation). Funding for this project came from the Deutsche Forschungsgemeinschaft grant ME2848-1-1 (to Hyuk Je Lee and A.M.) and the IMPRS Emergency Grant to F.R.

\section{AUTHOR CONTRIBUTIONS}

F.R., C.F. and A.M. designed the study. Morphological data were collected by F.R. and analysed by C.F. The analysis of eye asymmetry was performed by F.R. under supervision by C.F. Both F.R. and C.F. analysed the genetic data. F.R. drafted the manuscript. All authors edited and agreed to the manuscript.

\section{REFERENCES}

Adams DC, Otárola-Castillo E. 2013. geomorph: an R package for the collection and analysis of geometric morphometric shape data. Methods in Ecology and Evolution 4: 393-399. 
Alexander DH, Novembre J, Lange K. 2009. Fast modelbased estimation of ancestry in unrelated individuals. Genome Research 19: 1655-1664.

Anderson MJ. 2001. A new method for non-parametric multivariate analysis of variance. Austral Ecology 26: 32-46.

Arnqvist G, Martensson T. 1998. Measurement error in geometric morphometrics: empirical strategies to assess and reduce its impact on measures of shape. Acta Zoologica Academiae Scientiarum Hungaricae 44: 73-96.

Baird NA, Etter PD, Atwood TS, Currey MC, Shiver AL, Lewis ZA, Selker EU, Cresko WA, Johnson EA. 2008. Rapid SNP discovery and genetic mapping using sequenced RAD markers. PLoS ONE 3: e3376.

Benjamini Y, Hochberg Y. 1995. Controlling the false discovery rate: a practical and powerful approach to multiple testing. Journal of the Royal Statistical Society. Series B (Methodological) 57: 289-300.

Bianco IH, Wilson SW. 2009. The habenular nuclei: a conserved asymmetric relay station in the vertebrate brain. Philosophical Transactions of the Royal Society B: Biological Sciences 364: 1005-1020.

Bisazza A, Facchin L, Pignatti R, Vallortigara G. 1998a. Lateralization of detour behaviour in poeciliid fish: the effect of species, gender and sexual motivation. Behavioural Brain Research 91: 157-164.

Bisazza A, Pignatti R, Vallortigara G. 1997. Laterality in detour behaviour: interspecific variation in poeciliid fish. Animal Behaviour 54: 1273-1281.

Bisazza A, Rogers LJ, Vallortigara G. 1998b. The origins of cerebral asymmetry: a review of evidence of behavioural and brain lateralization in fishes, reptiles and amphibians. Neuroscience and Biobehavioral Reviews 22: 411-426.

Blake R, Law T, Chan K, Li J. 2005. Comparison of the prolonged swimming performances of closely related, morphologically distinct three-spined sticklebacks Gasterosteus spp. Journal of Fish Biology 67: 834-848.

Boily P, Magnan P. 2002. Relationship between individual variation in morphological characters and swimming costs in brook charr (Salvelinus fontinalis) and yellow perch (Perca flavescens). Journal of Experimental Biology 205: 1031-1036.

Bookstein FL. 1997. Landmark methods for forms without landmarks: morphometrics of group differences in outline shape. Medical Image Analysis 1: 225-243.

Borowsky R. 2008. Restoring sight in blind cavefish. Current biology: CB 18: R23-R24.

Boulesteix A-L. 2005. A note on between-group PCA. International Journal of Pure and Applied Mathematics 19: 359-366.

de Busserolles F, Fitzpatrick JL, Paxton JR, Marshall NJ, Collin SP. 2013. Eye-size variability in deep-sea lanternfishes (Myctophidae): an ecological and phylogenetic study. PLoS ONE 8: e58519.

Cardini A, Jansson AU, Elton S. 2007. A geometric morphometric approach to the study of ecogeographical and clinal variation in vervet monkeys. Journal of Biogeography 34: 1663-1678.

Carvajal-Rodriguez A, de Uña-Alvarez J. 2011. Assessing significance in high-throughput experiments by sequential goodness of fit and $q$-value estimation. PLoS ONE 6: e24700.
Catchen J, Hohenlohe PA, Bassham S, Amores A, Cresko WA. 2013. Stacks: an analysis tool set for population genomics. Molecular Ecology 22: 3124-3140.

Champ C, Wallis G, Vorobyev M, Siebeck U, Marshall J. 2014. Visual acuity in a species of coral reef fish: Rhinecanthus aculeatus. Brain, Behavior and Evolution 83: 31-42.

Chen Y-C, Cheng C-H, Chen G-D, Hung C-C, Yang C-H, Hwang S-PL, Kawakami K, Wu B-K, Huang C-J. 2009. Recapitulation of zebrafish sncga expression pattern and labeling the habenular complex in transgenic zebrafish using green fluorescent protein reporter gene. Developmental Dynamics 238: 746-754.

Clabaut C, Bunje PM, Salzburger W, Meyer A. 2007. Geometric morphometric analyses provide evidence for the adaptive character of the Tanganyikan cichlid fish radiations. Evolution 61: 560-578.

Coenen EJ, Hanek G, Kotilainen P. 1993. Shoreline classification of Lake Tanganyika based on the results of an aerial frame survey (29.09.92 - 03.10.92) Research for the management of the fisheries on Lake Tanganyika. GCP/ RAF/271/FIN-TD/1O(En). Bujumbura, Burundi: Finnish International Development Agency, Food and Agriculture Organization of the United Nations. Available at: $10 \mathrm{pp}$. http://www.fao.org/fi/ltr/FTP/TD10.PDF

Collyer ML, Sekora DJ, Adams DC. 2015. A method for analysis of phenotypic change for phenotypes described by highdimensional data. Heredity 115: 357-365.

Day JJ, Cotton JA, Barraclough TG. 2008. Tempo and mode of diversification of Lake Tanganyika cichlid fishes. PLOS ONE 3: e1730.

De Santi A, Sovrano VA, Bisazza A, Vallortigara G. 2001. Mosquitofish display differential left- and right-eye use during mirror image scrutiny and predator inspection responses. Animal Behaviour 61: 305-310.

Easter SS Jr, Johns PR, Baumann LR. 1977. Growth of the adult goldfish eye-I: optics. Vision Research 17: 469-477.

Elmer KR, Meyer A. 2011. Adaptation in the age of ecological genomics: insights from parallelism and convergence. Trends in Ecology \& Evolution 26: 298-306.

Excoffier L, Lischer HE. 2010. Arlequin suite ver 3.5: a new series of programs to perform population genetics analyses under Linux and Windows. Molecular Ecology Resources 10: 564-567.

Excoffier L, Smouse PE, Quattro JM. 1992. Analysis of molecular variance inferred from metric distances among DNA haplotypes: application to human mitochondrial DNA restriction data. Genetics 131: 479-491.

Facchin L, Bisazza A, Vallortigara G. 1999. What causes lateralization of detour behavior in fish? Evidence for asymmetries in eye use. Behavioural Brain Research 103: 229-234.

Falsetti AB, Sokal RR. 1993. Genetic structure of human populations in the British Isles. Annals of Human Biology 20: $215-229$.

Firmat C, Schliewen UK, Losseau M, Alibert P. 2012. Body shape differentiation at global and local geographic scales in the invasive cichlid Oreochromis mossambicus. Biological Journal of the Linnean Society 105: 369-381. 
Fisher R, Hogan JD. 2007. Morphological predictors of swimming speed: a case study of pre-settlement juvenile coral reef fishes. Journal of Experimental Biology 210: 2436-2443.

Fisher SR. 1958a. Statistical methods for research workers, 13th edition. Edinburgh, London: Oliver and Boyd.

Fisher SRA. 1958b. The genetical theory of natural selection. New York: Dover.

Fleiss JL, Shrout PE. 1977. The effects of measurement errors on some multivariate procedures. American Journal of Public Health 67: 1188-1191.

Franchini P, Colangelo P, Meyer A, Fruciano C. 2016. Chromosomal rearrangements, phenotypic variation and modularity: a case study from a contact zone between house mouse Robertsonian races in Central Italy. Ecology and Evolution 6: 1353-1362.

Franchini P, Fruciano C, Spreitzer ML, Jones JC, Elmer KR, Henning F, Meyer A. 2014. Genomic architecture of ecologically divergent body shape in a pair of sympatric crater lake cichlid fishes. Molecular Ecology 23: 1828-1845.

Fruciano C. 2016. Measurement error in geometric morphometrics. Development Genes and Evolution 226: 139-158.

Fruciano C, Celik MA, Butler K, Dooley T, Weisbecker V, Phillips MJ. 2017. Sharing is caring? Measurement error and the issues arising from combining 3D morphometric datasets. Ecology and Evolution 7: 7034-7046.

Fruciano C, Franchini P, Kovacova V, Elmer KR, Henning F, Meyer A. 2016a. Genetic linkage of distinct adaptive traits in sympatrically speciating crater lake cichlid fish. Nature Communications 7: 12736.

Fruciano C, Franchini P, Raffini F, Fan S, Meyer A. 2016b. Are sympatrically speciating Midas cichlid fish special? Patterns of morphological and genetic variation in the closely related species Archocentrus centrarchus. Ecology and Evolution 6: 4102-4114.

Fruciano C, Pappalardo AM, Tigano C, Ferrito V. 2014. Phylogeographical relationships of Sicilian brown trout and the effects of genetic introgression on morphospace occupation. Biological Journal of the Linnean Society 112: 387-398.

Fruciano C, Tigano C, Ferrito V. 2011a. Geographical and morphological variation within and between colour phases in Coris julis (L. 1758), a protogynous marine fish. Biological Journal of the Linnean Society 104: 148-162.

Fruciano C, Tigano C, Ferrito V. 2011b. Traditional and geometric morphometrics detect morphological variation of lower pharyngeal jaw in Coris julis (Teleostei, Labridae). Italian Journal of Zoology 78: 320-327.

Fruciano C, Tigano C, Ferrito V. 2012. Body shape variation and colour change during growth in a protogynous fish. Environmental Biology of Fishes 94: 615-622.

Fryer G, Iles T. 1972. The cichlid fishes of the great lakes of Africa, their biology and distribution. Edinburgh: Oliver and Boyd.

Fu YX, Li WH. 1993. Statistical tests of neutrality of mutations. Genetics 133: 693-709.

Futuyma DJ. 2009. Evolution. Sunderland, MA, USA: Sinauer Associates Inc.
Gross JB. 2016. Convergence and parallelism in astyanax cave-dwelling Fish. In: Pontarotti P, ed. Evolutionary biology. Cham: Springer, 105-119.

Gross JB, Krutzler AJ, Carlson BM. 2014. Complex craniofacial changes in blind cave-dwelling fish are mediated by genetically symmetric and asymmetric loci. Genetics 196: 1303-1319.

Guillot G, Rousset F. 2013. Dismantling the Mantel tests. Methods in Ecology and Evolution 4: 336-344.

Güntürkün O. 1997. Morphological asymmetries of the tectum opticum in the pigeon. Experimental Brain Research 116: $561-566$.

Gutiérrez-Ibáñez C, Reddon AR, Kreuzer MB, Wylie DR, Hurd PL. 2011. Variation in asymmetry of the habenular nucleus correlates with behavioural asymmetry in a Cichlid fish. Behavioural Brain Research 221: 189-196.

Hairston NG Jr, Li KT, Easter SS Jr. 1982. Fish vision and the detection of planktonic prey. Science 218: 1240-1242.

Henning F, Meyer A. 2014. The evolutionary genomics of cichlid fishes: explosive speciation and adaptation in the postgenomic era. Annual Review of Genomics and Human Genetics 15: 417-441.

Hori M. 1987. Mutualism and commensalism in a fish community in Lake Tanganyika. In: Kawano S, Connell JH, Hidaka T, eds. Evolution and coadaptation in biotic communities. University of Tokyo Press, Tokyo, 219-239.

Hori M. 1991. Feeding relationships among cichlid fishes in Lake Tanganyika: effects of intra- and interspecific variation of feeding behavior on their coexistence. INTECOL Bulletin 19: 89-102.

Hori M. 1993. Frequency-dependent natural selection in the handedness of scale-eating cichlid fish. Science 260: 216-219.

Hori M, Ochi H, Kohda M. 2007. Inheritance pattern of lateral dimorphism in two cichlids (a scale eater, Perissodus microlepis, and an herbivore, Neolamprologus moorii) in Lake Tanganyika. Zoological Science 24: 486-492.

Hori M, Watanabe K. 2000. Aggressive mimicry in the intrapopulational color variation of the Tanganyikan scale-eater Perissodus microlepis (Cichlidae). Environmental Biology of Fishes 59: 111-115.

Ichijo H, Nakamura T, Kawaguchi M, Takeuchi Y. 2017. An evolutionary hypothesis of binary opposition in functional incompatibility about habenular asymmetry in vertebrates. Frontiers in Neuroscience 10: 595.

Ingram T. 2015. Diversification of body shape in Sebastes rockfishes of the north-east Pacific. Biological Journal of the Linnean Society 116: 805-818.

International Lake Environment Commitee. 1999-2017. World lake database. Available at: http://wldb.ilec.or.jp/ Details/Data/8783/Lake\%20Tanganyika

Janzen T, Alzate A, Muschick M, Maan ME, van der Plas F, Etienne RS. 2017. Community assembly in Lake Tanganyika cichlid fish: quantifying the contributions of both niche-based and neutral processes. Ecology and Evolution 7: 1057-1067.

Jombart T, Ahmed I. 2011. adegenet 1.3-1: new tools for the analysis of genome-wide SNP data. Bioinformatics 27: 3070-3071. 
Kamvar ZN, Tabima JF, Grünwald NJ. 2014. Poppr: an R package for genetic analysis of populations with clonal, partially clonal, and/or sexual reproduction. PeerJ 2: e281.

Kerschbaumer M, Sturmbauer C. 2011. The utility of geometric morphometrics to elucidate pathways of cichlid fish evolution. International Journal of Evolutionary Biology 2011: 290245.

Klingenberg CP. 2011. MorphoJ: an integrated software package for geometric morphometrics. Molecular Ecology Resources 11: 353-357.

Klingenberg CP, Barluenga M, Meyer A. 2002. Shape analysis of symmetric structures: quantifying variation among individuals and asymmetry. Evolution 56: 1909-1920.

Klingenberg CP, McIntyre GS. 1998. Geometric morphometrics of developmental instability: analyzing patterns of fluctuating asymmetry with Procrustes methods. Evolution 52: 1363-1375.

Koblmüller S, Duftner N, Sefc KM, Aigner U, Rogetzer M, Sturmbauer C. 2009. Phylogeographic structure and gene flow in the scale-eating cichlid Perissodus microlepis (Teleostei, Perciformes, Cichlidae) in southern Lake Tanganyika. Zoologica Scripta 38: 257-268.

Koblmüller S, Egger B, Sturmbauer C, Sefe KM. 2007. Evolutionary history of Lake Tanganyika's scale-eating cichlid fishes. Molecular Phylogenetics and Evolution 44: 1295-1305.

Koblmüller S, Salzburger W, Obermüller B, Eigner E, Sturmbauer C, Sefc KM. 2011. Separated by sand, fused by dropping water: habitat barriers and fluctuating water levels steer the evolution of rock-dwelling cichlid populations in Lake Tanganyika. Molecular Ecology 20: 2272-2290.

Kocher TD. 2004. Adaptive evolution and explosive speciation: the cichlid fish model. Nature Reviews. Genetics 5: 288-298.

Kusche H, Lee HJ, Meyer A. 2012. Mouth asymmetry in the textbook example of scale-eating cichlid fish is not a discrete dimorphism after all. Proceedings of the Royal Society B: Biological Sciences 279: 4715-4723.

Langerhans RB. 2009. Morphology, performance, fitness: functional insight into a post-Pleistocene radiation of mosquitofish. Biology Letters 5: 488-491.

Lee HJ, Heim V, Meyer A. 2015. Genetic and environmental effects on the morphological asymmetry in the scale-eating cichlid fish, Perissodus microlepis. Ecology and Evolution 5: 4277-4286.

Lee HJ, Kusche H, Meyer A. 2012. Handed foraging behavior in scale-eating cichlid fish: its potential role in shaping morphological asymmetry. PLoS ONE 7: e44670.

Lee HJ, Pittlik S, Jones JC, Salzburger W, Barluenga M, Meyer A. 2010. Genetic support for random mating between left and right-mouth morphs in the dimorphic scale-eating cichlid fish Perissodus microlepis from Lake Tanganyika. Journal of Fish Biology 76: 1940-1957.

Lee HJ, Schneider RF, Manousaki T, Kang JH, Lein E, Franchini P, Meyer A. 2017. Lateralized feeding behavior is associated with asymmetrical neuroanatomy and lateralized gene expressions in the brain in scale-eating cichlid fish. Genome Biology and Evolution 9: 3122-3136.
Legendre P, Fortin MJ. 2010. Comparison of the Mantel test and alternative approaches for detecting complex multivariate relationships in the spatial analysis of genetic data. Molecular Ecology Resources 10: 831-844.

Maan ME, Sefc KM. 2013. Colour variation in cichlid fish: developmental mechanisms, selective pressures and evolutionary consequences. Seminars in Cell \& Developmental Biology 24: 516-528.

Mantel N. 1967. The detection of disease clustering and a generalized regression approach. Cancer Research 27: 209-220.

Matsui S, Takeuchi Y, Hori M. 2013. Relation between morphological antisymmetry and behavioral laterality in a poeciliid fish. Zoological Science 30: 613-618.

Matsumoto M, Hikosaka O. 2007. Lateral habenula as a source of negative reward signals in dopamine neurons. Nature 447: 1111-1115.

McGuigan K, Franklin CE, Moritz C, Blows MW. 2003. Adaptation of rainbow fish to lake and stream habitats. Evolution 57: 104-118.

Meyer A. 1993. Phylogenetic relationships and evolutionary processes in East African cichlid fishes. Trends in Ecology \& Evolution 8: 279-284.

Miller MR, Dunham JP, Amores A, Cresko WA, Johnson EA. 2007. Rapid and cost-effective polymorphism identification and genotyping using restriction site associated DNA (RAD) markers. Genome Research 17: 240-248.

Mitteroecker P, Bookstein F. 2011. Linear discrimination, ordination, and the visualization of selection gradients in modern morphometrics. Evolutionary Biology 38: 100-114.

Mizumori SJ, Baker PM. 2017. The lateral habenula and adaptive behaviors. Trends in Neurosciences 40: 481-493.

Munday PL, Eyre PJ, Jones GP. 2003. Ecological mechanisms for coexistence of colour polymorphism in a coral-reef fish: an experimental evaluation. Oecologia 137: 519-526.

Muschick M, Indermaur A, Salzburger W. 2012. Convergent evolution within an adaptive radiation of cichlid fishes. Current Biology: CB 22: 2362-2368.

Nakajima M, Matsuda H, Hori M. 2004. Persistence and fluctuation of lateral dimorphism in fishes. The American Naturalist 163: 692-698.

Nevado B, Mautner S, Sturmbauer C, Verheyen E. 2013. Water-level fluctuations and metapopulation dynamics as drivers of genetic diversity in populations of three Tanganyikan cichlid fish species. Molecular Ecology 22: 3933-3948.

Nielsen R, Beaumont MA. 2009. Statistical inferences in phylogeography. Molecular Ecology 18: 1034-1047.

Nshombo M, Yanagisawa Y, Nagoshi M. 1985. Scale eating in Perissodus microlepis (Cichlidae) and change of its food-habits with growth. Japanese Journal of Ichthyology 32: 66-73.

Oksanen J, Blanchet FG, Friendly M, Kindt R, Legendre P, McGlinn D, Minchin PR, O'Hara RB, Simpson GL, Solymos P, Stevens MHH, Szoecs E, Wagner H. 2016. vegan: community ecology package. $R$ package version 2.4-1. Available at: https://CRAN.R-project.org/package=vegan

Pakkasmaa S, Piironen J. 2000. Water velocity shapes juvenile salmonids. Evolutionary Ecology 14: 721-730. 
Palmer AR. 1994. Fluctuating asymmetry analyses: a primer. In: Markow T, ed. Developmental instability: its origins and evolutionary implications. Dordrecht, The Netherlands: Kluwer Academic Publishers, 335-364.

Palmer AR. 2010. Scale-eating cichlids: from hand(ed) to mouth. Journal of Biology 9: 11.

Palmer AR, Strobeck C. 2003. Fluctuating asymmetry analyses revisited. In: Polak M, ed. Developmental instability: causes and consequences. Oxford, UK: Oxford University Press, 279-319.

Paradis E, Claude J, Strimmer K. 2004. APE: analyses of phylogenetics and evolution in $\mathrm{R}$ language. Bioinformatics 20: 289-290.

Pembleton LW, Cogan NO, Forster JW. 2013. StAMPP: an $\mathrm{R}$ package for calculation of genetic differentiation and structure of mixed-ploidy level populations. Molecular Ecology Resources 13: 946-952.

Peterson BK, Weber JN, Kay EH, Fisher HS, Hoekstra HE. 2012. Double digest RADseq: an inexpensive method for de novo SNP discovery and genotyping in model and nonmodel species. PLoS ONE 7: e37135.

Pettersson LB, Hedenström A. 2000. Energetics, cost reduction and functional consequences of fish morphology. Proceedings of the Royal Society B: Biological Sciences 267: 759-764.

Pfeifer B, Wittelsbürger U, Ramos-Onsins SE, Lercher MJ. 2014. PopGenome: an efficient Swiss army knife for population genomic analyses in R. Molecular Biology and Evolution 31: 1929-1936.

Prevosti A, Ocaña J, Alonso G. 1975. Distances between populations of Drosophila subobscura, based on chromosome arrangement frequencies. Theoretical and Applied Genetics 45: 231-241.

R Core Team. 2016. $R$ : A language and environment for statistical computing. Vienna, Austria: R Foundation for Statistical Computing.

Raffini F, Fruciano C, Franchini P, Meyer A. 2017. Towards understanding the genetic basis of mouth asymmetry in the scale-eating cichlid Perissodus microlepis. Molecular Ecology 26: $77-91$.

Rogers LJ. 1989. Laterality in animals. International Journal of Comparative Psychology 3: 5-25.

Rogers LJ. 2017. A matter of degree: strength of brain asymmetry and behaviour. Symmetry 9: 57 .

Rohlf FJ. 2015. The tps series of software. Hystrix, the Italian Journal of Mammalogy 26: 9-12.

Rohlf FJ, Corti M. 2000. Use of two-block partial leastsquares to study covariation in shape. Systematic Biology 49: 740-753.

Rosenberg MS, Anderson CD. 2011. PASSaGE: pattern analysis, spatial statistics and geographic exegesis. Version 2. Methods in Ecology and Evolution 2: 229-232.

Rouleau S, Glémet H, Magnan P. 2010. Effects of morphology on swimming performance in wild and laboratory crosses of brook trout ecotypes. Functional Ecology 24: 310-321.

Saitou N, Nei M. 1987. The neighbor-joining method: a new method for reconstructing phylogenetic trees. Molecular Biology and Evolution 4: 406-425.
Salzburger W. 2009. The interaction of sexually and naturally selected traits in the adaptive radiations of cichlid fishes. Molecular Ecology 18: 169-185.

Salzburger W, Meyer A. 2004. The species flocks of East African cichlid fishes: recent advances in molecular phylogenetics and population genetics. Die Naturwissenschaften 91: 277-290.

Schlager S. 2017. Morpho and Rvcg-shape analysis in R. In: Zheng G, Li S, Székely G, eds. Statistical shape and deformation analysis: methods, implementation and applications. Cambridge, MA: Elsevier Academic Press.

Schmieder DA, Benítez HA, Borissov IM, Fruciano C. 2015. Bat species comparisons based on external morphology: a test of traditional versus geometric morphometric approaches. PLoS ONE 10: e0127043.

Seehausen 0. 2006. African cichlid fish: a model system in adaptive radiation research. Proceedings of the Royal Society B: Biological Sciences 273: 1987-1998.

Seetah TK, Cardini A, Miracle PT. 2012. Can morphospace shed light on cave bear spatial-temporal variation? Population dynamics of Ursus spelaeus from Romualdova pećina and Vindija, (Croatia). Journal of Archaeological Science 39: 500-510.

Sefc KM, Mattersdorfer K, Ziegelbecker A, Neuhüttler N, Steiner O, Goessler W, Koblmüller S. 2017. Shifting barriers and phenotypic diversification by hybridisation. Ecology Letters 20: 651-662.

Senay C, Harvey-Lavoie S, Macnaughton CJ, Bourque G, Boisclair D. 2017. Morphological differentiation in northern pike (Esox lucius L.): the influence of environmental conditions and sex on body shape. Canadian Journal of Zoology 95: $383-391$.

Shafer AB, Wolf JB. 2013. Widespread evidence for incipient ecological speciation: a meta-analysis of isolation-by-ecology. Ecology Letters 16: 940-950.

Shapiro SS, Wilk MB. 1965. An analysis of variance test for normality (complete samples). Biometrika 52: 591-611.

Smouse PE, Long JC, Sokal RR. 1986. Multiple regression and correlation extensions of the Mantel test of matrix correspondence. Systematic Zoology 35: 627-632.

Solt F, Hu Y. 2015. interplot: plot the effects of variables in interaction terms. The Comprehensive R Archive Network (CRAN). Available at: https://cran.r-project.org/web/packages/interplot/index.html

Soria-Carrasco V, Gompert Z, Comeault AA, Farkas TE, Parchman TL, Johnston JS, Buerkle CA, Feder JL, Bast J, Schwander T, Egan SP, Crespi BJ, Nosil P. 2014. Stick insect genomes reveal natural selection's role in parallel speciation. Science 344: 738-742.

Stewart TA, Albertson RC. 2010. Evolution of a unique predatory feeding apparatus: functional anatomy, development and a genetic locus for jaw laterality in Lake Tanganyika scale-eating cichlids. BMC Biology 8: 11 .

Sturmbauer C. 1998. Explosive speciation in cichlid fishes of the African Great Lakes: a dynamic model of adaptive radiation. Journal of Fish Biology 53: 18-36.

Tajima F. 1989. Statistical method for testing the neutral mutation hypothesis by DNA polymorphism. Genetics 123: $585-595$ 
Takahashi R, Moriwaki T, Hori M. 2007. Foraging behaviour and functional morphology of two scale-eating cichlids from Lake Tanganyika. Journal of Fish Biology 70: 1458-1469.

Takahashi T, Koblmüller S. 2011. The adaptive radiation of cichlid fish in Lake Tanganyika: a morphological perspective. International Journal of Evolutionary Biology 2011: 620754.

Takeuchi Y, Hori M, Oda Y. 2012. Lateralized kinematics of predation behavior in a Lake Tanganyika scale-eating cichlid fish. PLoS ONE 7: e29272.

Takeuchi Y, Hori M, Tada S, Oda Y. 2016. Acquisition of lateralized predation behavior associated with development of mouth asymmetry in a Lake Tanganyika scale-eating cichlid fish. PLoS ONE 11: e0147476.

Takeuchi Y, Oda Y. 2017. Lateralized scale-eating behaviour of cichlid is acquired by learning to use the naturally stronger side. Scientific Reports 7: 8984.

Tytell ED, Borazjani I, Sotiropoulos F, Baker TV, Anderson EJ, Lauder GV. 2010. Disentangling the functional roles of morphology and motion in the swimming of fish. Integrative and Comparative Biology 50: 1140-1154.

Valentin AE, Penin X, Chanut JP, Sévigny JM, Rohlf FJ. 2008. Arching effect on fish body shape in geometric morphometric studies. Journal of Fish Biology 73: 623-638.

Vallortigara G, Rogers LJ. 2005. Survival with an asymmetrical brain: advantages and disadvantages of cerebral lateralization. The Behavioral and Brain Sciences 28: 575-589; discussion 589 .

Van Dooren TJ, van Goor HA, van Putten M. 2010. Handedness and asymmetry in scale-eating cichlids: antisymmetries of different strength. Evolution 64: 2159-2165.
Veilleux CC, Kirk EC. 2014. Visual acuity in mammals: effects of eye size and ecology. Brain, Behavior and Evolution 83: $43-53$.

Webb PW. 1978. Fast-start performance and body form in seven species of teleost fish. Journal of Experimental Biology 74: 211-226.

Webb PW. 1982. Locomotor patterns in the evolution of actinopterygian fishes. The American Zoologist 22: 329-342.

Webb PW. 1984. Body form, locomotion and foraging in aquatic vertebrates. The American Zoologist 24: 107-120.

Webb PW, Kostecki PT, Stevens ED. 1984. The effect of size and swimming speed on locomotor kinematics of rainbow trout. Journal of Experimental Biology 109: 77-95.

Webb PW, Weihs D. 1986. Functional locomotor morphology of early life history stages of fishes. Transactions of the American Fisheries Society 115: 115-127.

Weir BS, Cockerham CC. 1984. Estimating $F$-statistics for the analysis of population structure. Evolution 38: 1358-1370.

Werner YL, Seifan T. 2006. Eye size in geckos: asymmetry, allometry, sexual dimorphism, and behavioral correlates. Journal of Morphology 267: 1486-1500.

Wilkens H, Strecker U. 2003. Convergent evolution of the cavefish Astyanax (Characidae, Teleostei): genetic evidence from reduced eye-size and pigmentation. Biological Journal of the Linnean Society 80: 545-554.

Wright S. 1949. The genetical structure of populations. Annals of Human Genetics 15: 323-354.

Zelditch ML, Swiderski DL, Sheets HD. 2004. Geometric morphometrics for biologists: a primer. New York and London: Academic Press.

\section{SUPPORTING INFORMATION}

Additional Supporting Information may be found in the online version of this article at the publisher's web-site:

Table S1. Detailed breakdown of the individual specimens used for the morphometric, genetic and combined analysis (indicated with a $\mathrm{X}$ in the dedicated column), respectively.

Table S2. Measurement error and variation between sides as quantified by Procrustes ANOVA and by an analogous of the intraclass correlation coefficient ('repeatability').

Table S3. Demographic analysis: number of segregating sites and neutrality indices for each population and country.

Table S4. Regression residuals of shape (Procrustes aligned coordinates) on centroid size, as used in the analyses of shape variation among sites and in the combined analyses of genetic and morphometric data.

Figure S1. Bearing plot of the correlation between morphometric and geographical distances (A) and genetic (Prevosti) and geographical distances (B).

Figure S2. Genetic relationships between the geographical sites: plot of the scores along the first two principal components of the genetic dataset.

Figure S3. Genetic relationships between the geographical sites: neighbor-joining tree.

Figure S4. Admixture cross-validation plot. $K$ is the number of clusters.

Figure S5. Aggressive mimicry in Perissodus microlepis. This cichlid fish (second, fourth, fifth and sixth specimens from top) resembles the poeciliid Lamprichthys tanganicanus (first and second from top).

\section{SHARED DATA}

Data on individual specimens (unique identity, Illumina barcode, sampling location, mouth bending angle and Procrustes aligned coordinates on centroid size) used in this study are provided in the Supporting Information (Tables S1 and S4). Raw Illumina sequences have been archived to the National Center for Biotechnology Information (NCBI)'s Sequence Read Archive (SRA) database with Accession no. PRJNA324541. 